\title{
SIMULTANEOUS MEASUREMENT OF EFFECTIVE RENAL BLOOD FLOW AND CARDIAC OUTPUT IN RESTING NORMAL SUBJECTS AND PATIENTS WITH ESSEN- TIAL HYPERTENSION ${ }^{1}$
}

\author{
By ALFRED A. BOLOMEY,2 ALEXANDER J. MICHIE,8 CATHARINE MICHIE,4 \\ ERNEST S. BREED, GEORGE E. SCHREINER, AND HENRY D. LAUSON 5 \\ (From the Departments of Physiology and Medicine, New York University College of Medicine, \\ and the Third Medical Division [New York University] of Bellevue Hospital, \\ New York City)
}

(Received for publication May 14, 1948)

Unpublished data of Bradley and associates (1) indicate that about 25 to 30 per cent of the cardiac output, as measured by the ballistocardiograph (2), perfuses the kidney of healthy adults at rest. This figure has been reported in a review on renal physiology (3). Levy and Blalock (4) obtained an average value of 18.5 per cent in unanesthetized dogs, using the catheterization technique or heart puncture and the direct Fick principle for the determination of the cardiac output. When normal human values for the resting cardiac output obtained by the direct Fick procedure $(5,6)$ are divided into the normal human values for effective renal blood flow (7), the resulting effective renal fraction is about 19 to 20 per cent.

The present investigation was undertaken to make these measurements simultaneously in a series of normal subjects and in patients with essential hypertension, using the cardiac catheterization technique $(8,9)$ and the direct Fick principle for the measurements of the cardiac output.

\section{METHODS}

All studies were made during the morning at least 12 hours after the previous meal.

Effective renal blood flow was determined from the renal plasma clearance of $p$-aminohippurate or diodrast and from the hematocrit (10). At the same time, the glomerular filtration rate was measured by the renal plasma clearance of mannitol, inulin (10), or sodium

1 This investigation was aided by a grant from the Commonwealth Fund.

2 Present address: Permanente Foundation Hospital, Oakland, California.

8 Present address: University of Pennsylvania Hospital, Department of Urology, Philadelphia, $\mathrm{Pa}$.

4 Present address: Department of Physiology, Temple University School of Medicine, Philadelphia, $\mathrm{Pa}$.

5 Present address: Hospital of the Rockefeller Institute for Medical Research, New York City. thiosulfate (11). In about two-thirds of the cases the effective tubular excretory mass was determined from the excretion at high plasma concentrations of p-aminohippurate $\left(T_{\left.\mathrm{m}_{\mathbf{A B}}\right)}\right.$ or of diodrast $\left(\mathrm{T}_{\mathrm{m}}\right)(10,12)$. Urethral catheterization with saline and air washout was employed routinely.

Mixed venous blood for oxygen analysis was obtained through a cardiac catheter introduced into the pulmonary artery, the right ventricle, or failing these, the right auricle. The exact position in the auricle was checked fluoroscopically immediately before or after sampling to assure optimal placement $(5,10)$. After insertion of the cardiac and bladder catheters and placement of the indwelling femoral arterial needle, ${ }^{6}$ a rest period of 30 minutes ensued, following which the patient was familiarized with the noseclip, mouthpiece, and with bedside procedure. Several trial collections of expired air were obtained prior to the definitive collection, in order to minimize anxiety and to prove the stability of the ventilation, respiratory and heart rates. Arterial and mixed venous blood were drawn simultaneously under oil during the two-minute collection of expired air. Blood oxygen contents were determined in duplicate by the method of Van Slyke and Neill (13). Oxygen consumption was calculated from gas analysis of the expired air by the Haldane method (13).

Shortly before and after the above procedure, the arterial pressure was recorded optically by the Hamilton manometer (14), or the mean pressure was read directly from a calibrated aneroid manometer connected to the arterial needle through a short rubber tubing containing air which damped the pressure pulse almost completely. In the former case, the mean pressure was calculated from the weight of a representative sample cut out carefully from the photographic record. In a few subjects the arterial pressure was determined by cuff sphygmomanometry, the mean pressure being estimated as $\mathrm{Pm}=$ $P_{D}+0.4\left(P_{B}-P_{D}\right)$. The total peripheral resistance was calculated by dividing the mean arterial pressure by the cardiac output per 1.73 sq.m. and is expressed as dynes $\mathrm{cm}^{-5} \mathrm{sec}$. (absolute unit).

The metabolic rate was calculated from the minute volume of oxygen consumed and the assumed R.Q. of

- Specially designed by Becton, Dickinson and Company. 


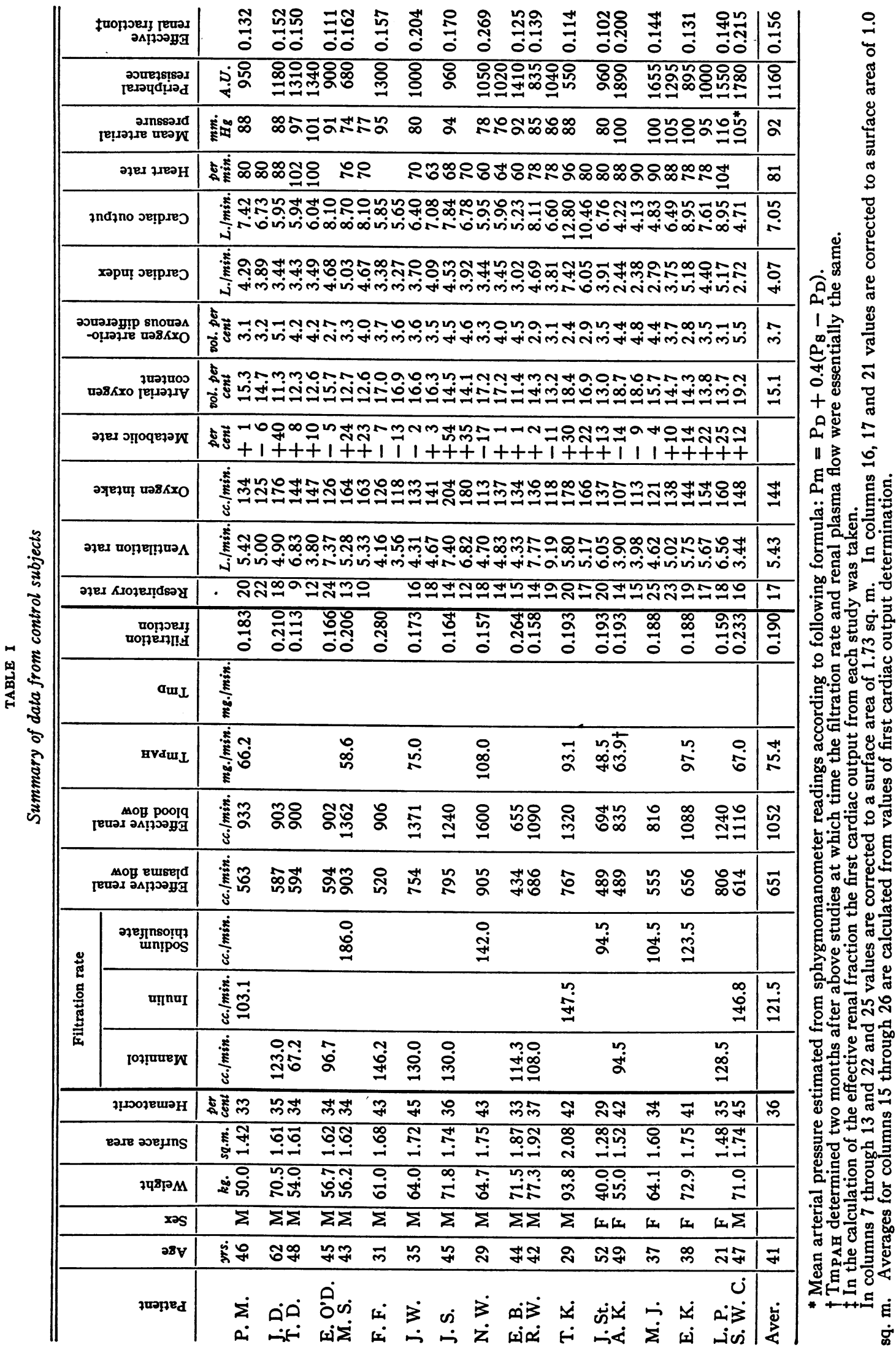




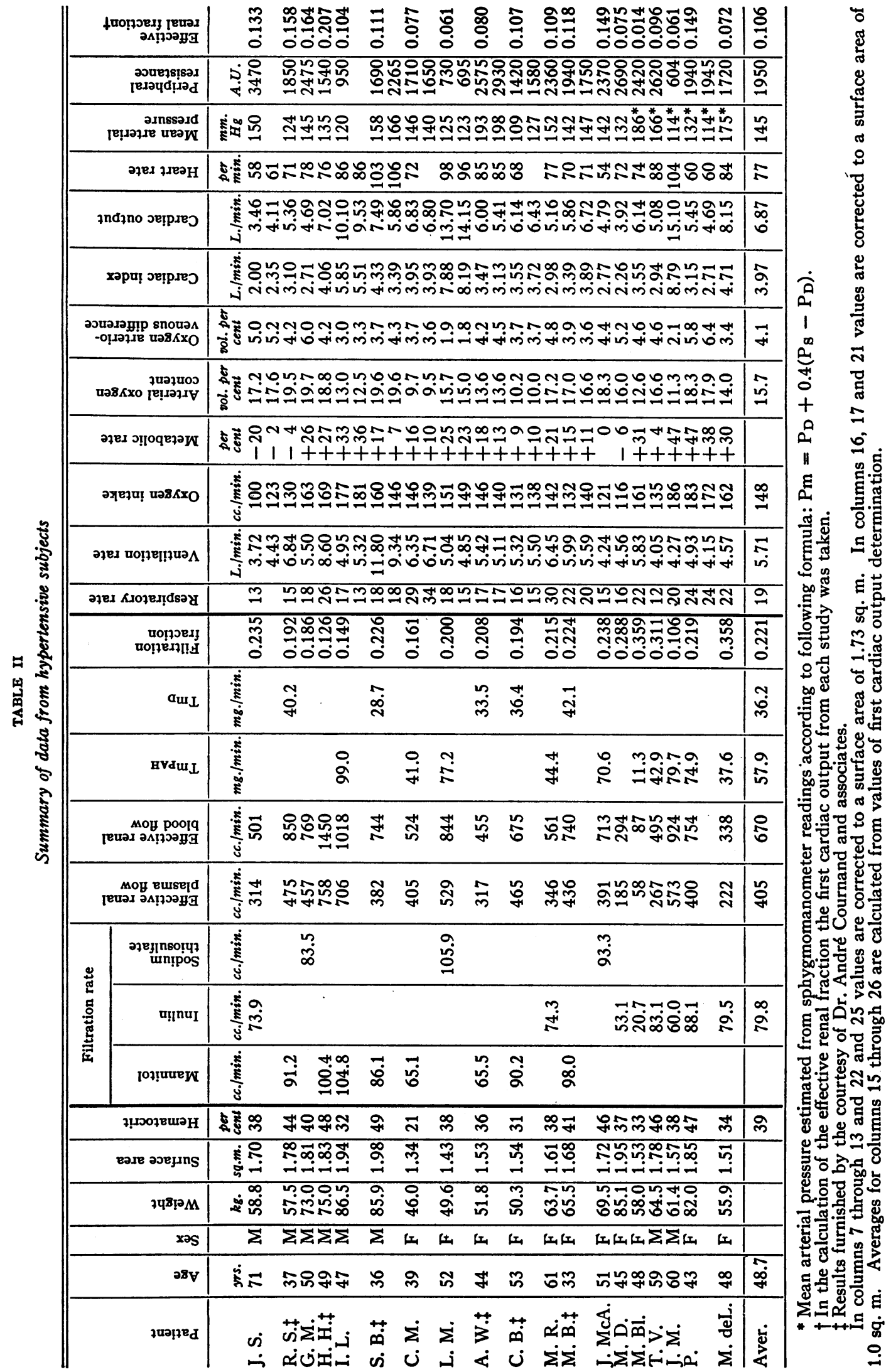


0.82. The observed R.Q. was not used for this purpose because the short collection period makes the $\mathrm{CO}_{2}$ value too dependent on variations in the respiratory pattern, and therefore not a reliable measure of metabolic $\mathrm{CO}_{2}$ production. The values of ventilation rate and oxygen consumption are corrected to saturation at $37^{\circ} \mathrm{C}$. and prevailing barometric pressure.

\section{CLINICAL SUBJECTS}

All subjects were patients of the Third (New York University) Medical Division of Bellevue Hospital. The normal subjects are representative of the convalescent ward population of a large city hospital. Most of them had had an upper respiratory infection or acute alcoholism. There was one each with a diagnosis of mild anxiety neurosis, headache of unknown cause and without neurological signs, central nervous system degenerative disease, mild chronic cholecystitis, old quiescent small lung abscess, and central nervous system syphilis. In addition, six patients, convalescent from traumatic or hemorrhagic shock, who were studied 17 to 76 days after injury, are included in the present series by the kind permission of Drs. André Cournand, D. W. Richards, Jr., and their co-workers $(15,16)$. None of the normal subjects had any evidence of cardiovascular or renal disease. All had been afebrile and all but two were ambulatory for at least a week prior to study.

Most of the patients with essential hypertension were admitted to Bellevue from the New York University Hypertension and Nephritis Clinic for the express purpose of study. None presented evidence of cardiac insufficiency.

\section{RESULTS}

Tables I and II present the data from each subject. The more pertinent data are presented in the form of frequency diagrams in Figures 1 and 2.

The control and hypertensive groups are fairly comparable with respect to distribution of hematocrit, metabolic rate and pulse rate. This is considered essential for the comparison of the other values, in so far as deviations from accepted normal standards in these three might be expected to affect cardiac output and renal function. The hypertensive group averages 7.5 years older, and contains a higher proportion of women than the control group. The two groups are reason- ably comparable as regards nutritional status and general health exclusive of hypertensive disease.

The cardiac output, expressed as liters per minute per square meter of body surface area, averages 4.07 in the control group as compared to 3.97 in the hypertensive group. The difference is not significant. This is in accord with the observations of previous investigators $(17,18)$.

Mean arterial pressure is, of course, markedly higher in the patients with essential hypertension. Since the cardiac output is about the same in both groups, the average calculated total peripheral resistance is elevated in the hypertensive group to about the same extent as is the arterial pressure.

Effective renal blood flow is within the normal range of plus or minus twice the standard deviation from the respective male and female means $(7,12)$ in 17 and below in only one of the control subjects. Ten of the hypertensive patients have renal blood flow within the normal range; eight are below it, and none exceeds it. Moreover, in all but one of the hypertensive patients the values are less than the normal mean.

The effective renal plasma flow is within the normal range in all of the control subjects, whereas it is below this range in eight of the 19 hypertensives.

The filtration rate is below the normal range in one control subject and above in another. In the rest, it is well within the normal range. Among the hypertensives, 11 fall below the range and none exceeds the normal mean.

Seven of the nine determinations of $T_{\mathbf{P A B}}$ made in the control group fall in the normal range reported by Chasis, Redish, Goldring, Ranges and Smith (12), while five of the ten determinations in hypertensive patients lie below this range. Diodrast $\mathrm{Tm}$, measured in five hypertensives, is in the normal range in four and below normal in one.

The filtration fraction (filtration rate/effective plasma flow) averages 0.190 in the control group and 0.221 in the hypertensive group. The difference between normal and hypertensive patients is less striking than that observed by Goldring and Chasis (10).

The effective renal fraction (effective renal blood flow/cardiac output) was calculated from the average effective renal blood flow and from 

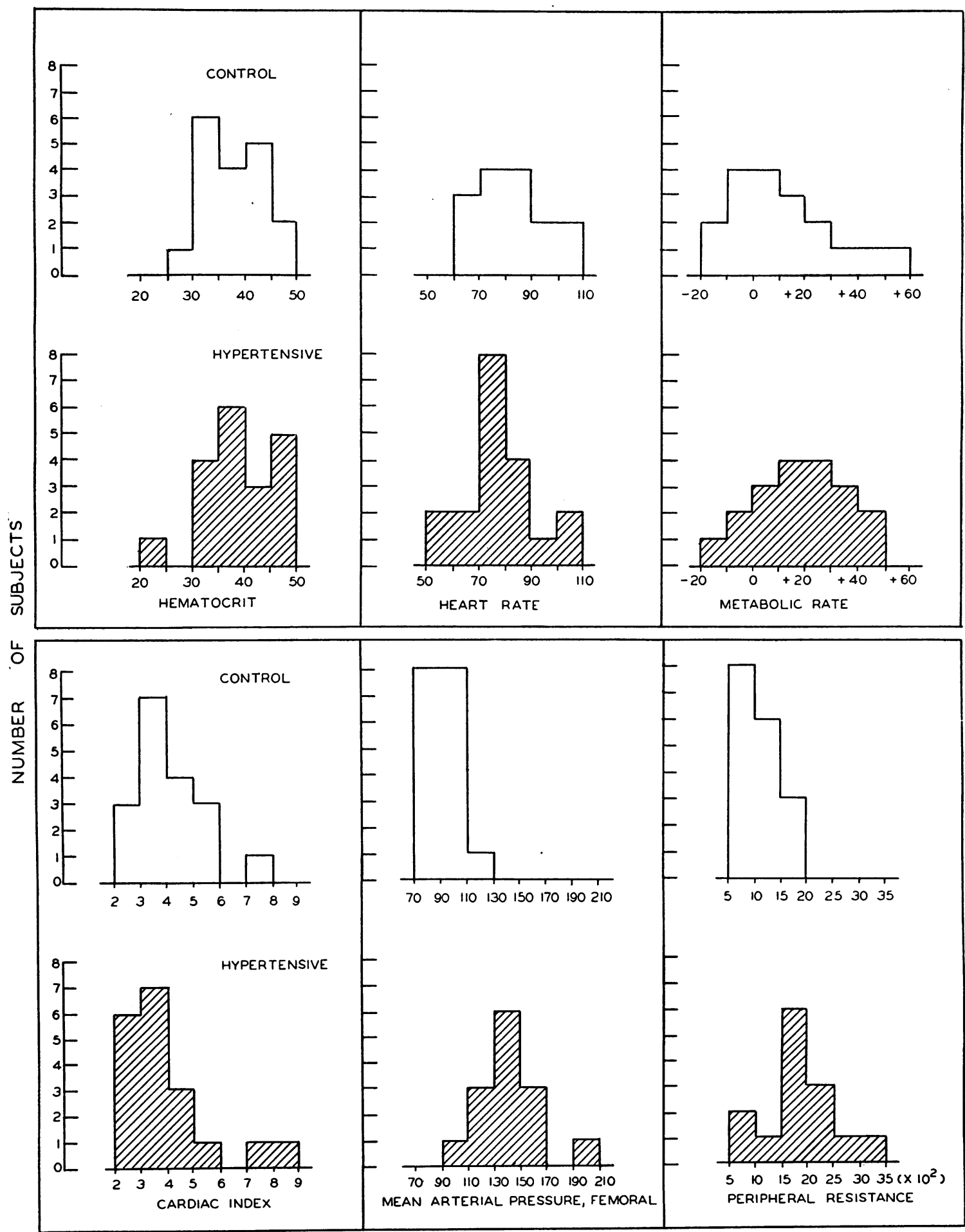

Fig. 1. Frequency Distribution of Observed Physiological Variables in Control and HYPERTENSIVE SUBJECTS

The values shown are those obtained in connection with the first cardiac output determination. 


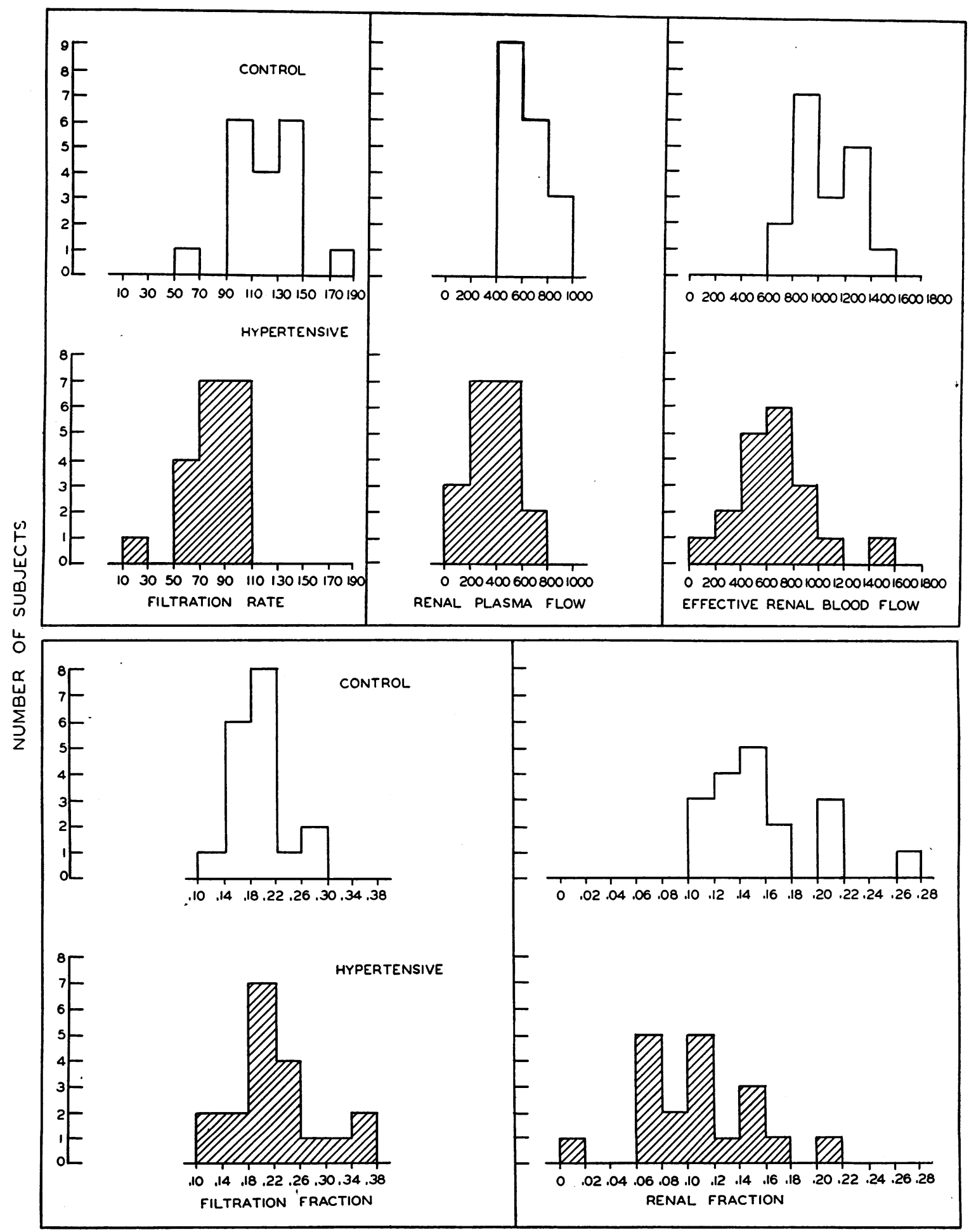

Fig. 2. Frequency Distribution of Observed Physiological Variables in Control and HYPERTENSIVE SUBJECTS 
the first cardiac output determination on each individual. It varies from 0.102 to 0.269 , with an over-all average of 0.156 in the control group. The corresponding range for the hypertensives is from 0.014 to 0.207 , with an average of 0.106 . This average figure of course has iittle meaning, since the renal blood flow must necessarily decrease with the progressive parenchymal destruction known to be associated with this disease, and if the cardiac output is maintained, the effective renal fraction will decrease correspondingly. ${ }^{7}$

\section{DISCUSSION}

As noted in the introductory paragraph, the normal effective renal fraction in the resting postabsorptive condition averages about 0.19 to 0.20 if the normal mean effective renal blood flow reported by Smith (7) is divided by the normal mean cardiac output reported by Cournand, Riley, Breed, Baldwin and Richards (5) and by Stead et al. (6).

The lower average of 0.156 for the effective renal fraction in the present control series may be due in part to the influence of moderate anemia on the renal blood flow of some of the subjects. Such a possibility would be suggested from the data of Bradley and Bradley (19). A more important factor, however, is the elevation of the cardiac output. From the data in Table I and from those of Brannon, Merrill, Warren and Stead (20) it would appear that anemia of the moderate degree encountered in these subjects does not, by itself, affect the cardiac output. On

\footnotetext{
7 It should perhaps be emphasized that the term "effective" renal blood flow indicates the volume per minute of blood perfusing functioning excretory tissue (22). On the same basis, "effective" renal fraction is defined as the fraction of the cardiac output which perfuses the functioning renal excretory tissue. If the renal extraction of p-aminohippurate is in the normal range of about 85 to 100 per cent $(23,24)$, the "effective" renal blood flow and "effective" renal fraction represent 85 to 100 per cent of the "total" renal blood flow and "total" renal fraction. If the extraction is less than normal, the relationship between the "effective" and "total" values will be correspondingly altered. Bradley (23) found that the extraction was normal in 12 of 14 cases of essential hypertension and was reduced only in two patients, both of whom had advanced renal disease with uremia. Judging from Bradley's data, it seems probable that the extraction is moderately or greatly reduced in M.B1. Furthermore, it is possible that the extraction may be slightly to moderately decreased in M.D., T.V. and M. deL. (see Table II).
}

the other hand, anxiety, tenseness, annoyance, etc., which frequently complicate this type of investigation, would be expected to raise the cardiac output. This view is supported by the recent studies of Stead et al. (6), and of Hickam, Cargill and Golden (21).

It is believed that our control and hypertensive groups are reasonably comparable as regards anemia and anxiety, in so far as may be inferred from the hematocrit, metabolic rate and heart rate. Since the average cardiac output is the same in both groups, it is apparent that the decreased average effective renal fraction in the hypertensive group is attributable to the diminished effective renal blood flow known to accompany this disease.

\section{SUMMARY}

Results of simultaneously determined cardiac output by the direct Fick method and renal clearances are presented for 18 nonhypertensive and for 19 hypertensive subjects in the post-absorptive period at rest.

The cardiac indices of control and hypertensive subjects are within the same range, the average for each group being 4.07 and 3.97 liters, respectively.

The average effective renal fraction of the control subjects $(0.156$, range 0.102 to 0.269$)$ is lower than that calculated from non-simultaneous determinations reported in the literature. This is believed to be a consequence of an increase in average cardiac output associated with the multiple manipulations of simultaneous study, and, to a lesser extent, of the moderate anemia of some of the subjects which may have led to some reduction in the effective renal blood flow.

An additional reduction in the effective renal fraction in the hypertensive subjects (average 0.106 , range 0.014 . to 0.207 ) results from the functional ischemia and progressive destruction of renal parenchyma characteristic of the disease, and in advanced hypertensive disease the effective renal fraction may be less than 0.020 .

\section{BIBLIOGRAPHY}

1. Bradley, S., Unpublished data.

2. Starr, I., Rawson, A. J., Schroeder, H. A., and Joseph, N. R., Studies on the estimation of the cardiac output in man, and of the abnormalities in 
cardiac function from the heart's recoil and the blood's impacts; the ballistocardiogram. Am. J. Physiol., 1939, 127, 1.

3. Pitts, R. F., Kidney. Ann. Rev. Physiol., 1946, 8, 199.

4. Levy, S. E., and Blalock, A., Fractionation of the output of the heart and of the oxygen consumption of normal unanesthetized dogs. Am. J. Physiol., 1937, 118, 368.

5. Cournand, A., Riley, R. L., Breed, E. S., Baldwin, E. de F., and Richards, D. W., Jr., Measurement of cardiac output in man using the technique of catheterization of the right auricle or ventricle. J. Clin. Invest., 1945, 24, 106.

6. Stead, E. A., Warren, J. V., Merrill, A. J., and Brannon, E. S., The cardiac output in male subjects as measured by the technique of right atrial catheterization. Normal values with observations on the effect of anxiety and tilting. J. Clin. Invest., 1945, 24, 326.

7. Smith, H. W., Lectures on the kidney. University Extension Division, Univ. of Kansas, Lawrence, Kansas, 1943, 96-97.

8. Cournand, A., and Ranges, H. A., Catheterization of the right auricle in man. Proc. Soc. Exper. Biol. and Med., 1941, 46, 462.

9. Cournand, A., Measurement of the cardiac output in man using the right heart catheterization. Federation Proc., 1945, 4, No. 2, 207.

10. Goldring, W., and Chasis, $H .$, Hypertension and Hypertensive Disease. The Commonwealth Fund, New York, 1944.

11. Gilman, A., Philips, F. S., and Koelle, E., The renal clearance of thiosulfate with observations on its volume distribution. Am. J. Physiol., 1946, 146, 348.

12. Chasis, H., Redish, J., Goldring, W., Ranges, $H$., and Smith, H. W., The use of sodium p-aminohippurate for the functional evaluation of the human kidney. J. Clin. Invest., 1945, 24, 583.

13. Peters, J. P., and Van Slyke, D. D., Quantitative Clinical Chemistry: Vol. II, Methods. The Williams and Wilkins Co., Baltimore, 1932.

14. Hamilton, W. F., Brewer, G., and Brotman, I., Pressure pulse contours in the intact animal. I.
Analytical description of a high frequency hypodermic manometer. Am. J. Physiol., 1934, 107, 427.

15. Cournand, A., Riley, R. L., Bradley, S. E., Breed, E. S., Noble, R. P., Lauson, H. D., Gregersen, M. I., and Richards, D. W., Jr., Studies of the circulation in clinical shock. Surgery, 1943, 13, 964.

16. Lauson, H. D., Bradley, S. E., and Cournand, A., The renal circulation in shock. J. Clin. Invest., 1944, 23, 381.

17. Steele, J. M., The circulation in hypertension. Publication of the Am. Assoc. for the Advancement of Science, 1940, 13, 289.

18. Holman, D. V., and Page, I. H., Cardiac output in arterial hypertension; the study of arterial hypertension produced by constricting renal arteries in unanesthetized and anesthetized (pentobarbital) dogs. Am. Heart J., 1938, 16, 321.

19. Bradley, S. E., and Bradley, G. P., Renal function during chronic anemia in man. Blood, 1947, 2, 192.

20. Brannon, E. S., Merrill, A. J., Warren, J. V., and Stead, E. A., Jr., The cardiac output in patients with chronic anemia as measured by the technique of right atrial catheterization. J. Clin. Invest., 1945, 24, 332.

21. Hickam, J. B., Cargill, W. H., and Golden, A., Cardiovascular reactions to emotional stimuli. Effect on cardiac output, arteriovenous oxygen difference, arterial pressure and peripheral resistance. J. Clin. Invest., 1948, 27, 290.

22. Smith, Homer, W., Note on the interpretation of clearance methods in the diseased kidney. J. Clin. Invest., 1941, 20, 631.

23. Bradley, S. E., The validity of the clearance technique in the measurement of renal blood flow in normal man and in patients with essential hypertension. Transactions of the First Conference on Factors Regulating Blood Pressure, Josiah Macy, Jr. Foundation, New York, 1947, 118-124.

24. Warren, J. V., Brannon, E. S., and Merrill, A. J., A method of obtaining renal venous blood in unanesthetized persons, with observations on the extraction of oxygen and sodium para-amino hippurate. Science, 1944, 100, 108. 